\title{
Using Environmental Print to Enhance Emergent Literacy
} and Print Motivation

Michelle M. Neumann, Michelle Hood, \& Ruth M. Ford

School of Applied Psychology, Griffith University, QLD 4222, Australia

Please direct correspondence to:

Michelle Neumann: School of Applied Psychology, Griffith University, QLD 4222, Australia. E-mail: michelle.neumann@griffithuni.edu.au

Facsimile: +61(0)7 5552 8291, Telephone: +61(0)7 55528052 . 


\begin{abstract}
Given the ubiquitous and salient nature of environmental print, it has the potential to scaffold emergent literacy in young children. This randomised control study evaluated the effects of using environmental print compared to standard print (the same labels in manuscript form) in an 8-week intervention (30 minutes per week) to foster 3- to 4-year-old's $(N=73)$ emergent literacy skills and print motivation. At the end of the intervention, the environmental print group outperformed a no intervention control group on letter sound knowledge, letter writing, environmental print and standard print reading, print concepts, and print motivation, even after controlling for receptive language abilities. Most of these gains were sustained two months later. The environmental print group also outperformed the standard print group on print motivation and environmental print reading at post-test, and on print motivation, environmental print and standard print reading, and letter writing at 2-month follow-up. Environmental print may be more effective than standard print in enhancing print motivation and aspects of emergent literacy in young children due to its contextual nature.
\end{abstract}

Key words: environmental print, emergent literacy skills, print motivation, preschool intervention. 


\section{Using Environmental Print to Enhance Emergent Literacy and Print Motivation}

In recent years, educators, researchers, and government bodies have focused on the acquisition of emergent literacy skills in the pre-school years, because of their impact on a child's future reading ability (Australian Government, 2005; Snow, Burns, \& Griffin, 1998). Emergent literacy skills include alphabet knowledge (e.g., Levin, Shatil-Carmon, \& AsifRave, 2006), print concepts (e.g., Justice \& Ezell, 2001), and emergent writing (e.g., Aram \& Biron, 2004). These develop prior to school entry through socio-cultural experiences with print (Bowman \& Treiman, 2004; Teale \& Sulzby, 1986; Whitehurst \& Lonigan, 1998). Young children are exposed to print not only through storybooks (Justice \& Ezell, 2002) but also through environmental print (Vera, 2011). Environmental print includes labels and logos on food, toy packaging, clothing, road signs, and billboards (Horner, 2005). It has been suggested that environmental print helps children realize that print is meaningful and functional (Harste, Burke, \& Woodward, 1981; Vukelich, Christie, \& Enz, 2008). It has also been argued that if a more knowledgeable person scaffolds children's interactions with environmental print, the children may learn to separate and identify letters from their nonprint context (Adams, 1990; Baker, Fernandez-Fein, Scher, \& Williams, 1998). However, little empirical evidence exists to support these claims. We report on a randomized control study of the effects of a pre-school intervention using environmental print on emergent literacy.

Environmental print provides children with some of their earliest print experiences (Neumann, Hood, Ford, \& Neumann, 2011; Whitehurst \& Lonigan, 1998). In context, this type of print is large and bold and appears in a variety of sizes, colours, shapes, and fonts, generally in capital letters. Young children initially use the salient visual cues and logos in environmental print to decode it rather than relying on letter-sound analysis, which is not yet developed. This is known as logographic reading (Frith, 1985). This is confirmed by 
evidence that young children can no longer read environmental print words when the contextual cues are removed and the words are presented in standard black and white manuscript form (e.g., Goodall, 1984; Masonheimer, Drum, \& Ehri, 1984). In addition, children do not notice letter changes in environmental print (e.g., changing PEPSI to XEPSI; Masonheimer et al., 1984), indicating they are reading logographically.

A few studies have investigated the use of environmental print (e.g., toy and product logos) to foster emergent literacy (Prior, 2003; Salewski, 1995; Vera, 2011; Wepner, 1985). These short-term quasi-experimental interventions conducted in preschool settings showed that environmental print may enhance children's logographic reading skills, letter recognition, and print concepts (Prior, 2003; Salewski, 1995; Vera, 2011; Wepner, 1985), as well as their attitude to reading (Wepner, 1985). However, there were several methodological issues with these studies. For example, Wepner (1985) did not test for the statistical significance of post-intervention differences so it is unclear whether the differences were greater than would be expected by chance. Neither Salewski (1995), Prior (2003), nor Vera (2011) randomly assigned participants to intervention and control groups; therefore, it is unclear to what extent pre-existing group differences explained the post-intervention differences (although Prior, 2003, provided the strongest evidence of pre-post changes in environmental print reading for the intervention groups). In Vera's (2011) study, both environmental print and storybooks were used so the independent contribution of environmental print to improvements in emergent literacy could not be determined. Therefore, further research is needed that randomly assigns participants to groups and uses pure environmental print activities to clarify the role of environmental print in fostering emergent literacy.

A further limitation of past studies is that they only tested a narrow range of emergent literacy skills and did not examine letter writing or print motivation (although Wepner, 1985, 
did measure attitudes to reading). Early writing and reading development are strongly related (Clay, 1998; Teale \& Sulzby, 1986) and letter writing is positively related to alphabet knowledge (Ritchey, 2008). To date, only a few case studies have demonstrated children's use of environmental print in their writing (e.g., Chan, Juan, \& Lai Foon, 2008; Neumann \& Neumann, 2010). Print motivation refers to a child's relative interest in reading and writing activities (Whitehurst \& Lonigan, 1998). Children's interest in and interactions with surrounding print are important behavioural indices of emerging motivations for reading (Baker, Scher, \& Mackler, 1997). The attractive visual nature of environmental print suggests that it should promote print motivation (Salewski, 1995; Vera, 2011; Wepner, 1985) yet no previous research has examined this. The current study incorporated a broader range of emergent literacy outcomes, including letter writing and print motivation.

One of the potential benefits of using environmental print to foster emergent literacy is that environmental print provides children with opportunities to explore print almost everywhere in their natural environment. This ubiquity of environmental print increases opportunities for interactions with letters embedded in these logos and this may, as a result, foster greater growth in emergent literacy than relying on exploring print in books. On the other hand, it has been argued that the bright colours and logos of environmental print might distract children from examining the print itself, thereby providing little benefit to letter and word learning (Ehri \& Roberts, 2006). Thus, although environmental print is highly salient in a child's environment (Horner, 2005) potentially providing more opportunities for interactions, it has been argued that standard print labels without distracting logos may be more beneficial to preschooler's letter and word learning (Share \& Gur, 1999). The current study tested these two competing hypotheses directly by using the same training words presented either as logos complete with contextual cues (environmental print) or in standard manuscript font without these contextual cues. 


\section{The Present Study}

This study built on existing research to determine the extent to which environmental print enhances emergent literacy and print motivation in preschoolers. A methodologically strong design was used. Children were randomly assigned to either an environmental print or a standard print intervention group or a no-intervention control group. The intervention groups received 30-minute weekly instruction for 8 weeks. Instruction was identical, and involved letter training, except one group used environmental print and the other used the identical words in standard manuscript form. This allowed us to examine the effectiveness of using environmental print relative to using standard print or no intervention, without potentially confounding effects of incorporating other forms of print like storybooks.

Whereas previous studies (Prior, 2003; Salewski, 1995; Vera, 2011; Wepner, 1985) only compared a narrow range of emergent literacy skills prior to and immediately following the intervention, we compared a broader range of skills prior to, immediately after, and twomonths after the intervention. Skills assessed were letter sound and name knowledge, letter writing, print concepts, print motivation, environmental print reading, and standard print reading. The inclusion of the second post-intervention test enabled us to test the hypothesis that the wide availability of environmental print should increase independent learning activities for children trained to use this form of print as a literacy learning tool and, thereby, their emergent literacy.

We reasoned that if environmental print provides more learning opportunities in a child's daily surroundings then training children using environmental print should result in better short and medium-term outcomes compared to using standard print or no intervention. This is because environmental print is visually attractive and ubiquitous and children trained in identifying letters embedded in environmental print words may continue to seek them out, 
thus initiating their own interactions with print outside the classroom. We expected letter knowledge, print concepts, and print motivation to improve based on prior evidence that environmental print enhanced these (Salewski, 1995; Vera, 2011; Wepner, 1985). The environmental print group was expected to show improved reading of environmental print words in context and in standard print because it has been shown that exposure to logos improves children's logographic reading (Prior, 2003; Wepner, 1985) and can transfer to reading words in manuscript form (Cronin, Farrell, \& Delaney, 1999). In contrast, if environmental print logos distract children from attending to the embedded letters then instruction in standard print should result in enhanced outcomes over environmental print. Finally, we predicted that instruction using either print type will be more beneficial to children's literacy development than no intervention.

\section{Method}

\section{Participants}

The sample comprised 73 pre-school aged children $(M=4.12$ years; $S D=0.24$; range $=3.53-4.81$ years). The children (37 boys, 36 girls) were recruited from four preschools on the Gold Coast in Queensland, Australia. In Australia, there is no formal instruction in reading or writing at preschool. To ensure all children were typically developing, parents were asked about any known speech or language, hearing (e.g., having grommets fitted due to chronic ear infections), or eyesight problems or serious illness or injury likely to affect normal development. Children with such problems were excluded, as were participants whose receptive vocabulary scores fell below 80 on the Peabody Picture Vocabulary Test $4^{\text {th }}$ Edition (PPVT-IV, Dunn \& Dunn, 2007) or for whom English was not their main language.

Most mothers were married or in a de facto relationship (79.5\%), with $16.4 \%$ divorced or separated, and $4.1 \%$ single or never married. Family socio-economic status (SES) 
was calculated using the Hollingshead 4-factor Index (Hollingshead, 1975) based on parental education and occupation. The mean fell in the middle SES range of 40 to $54(M=46.30 ; S D$ $=9.91 ;$ Range $14-61)$. Of the mothers, $4.2 \%$ completed Grades 7 to $9,11.1 \%$ completed Grades 10 to $11,13.8 \%$ completed secondary school, $43.1 \%$ had partial college/specialised training, $18.1 \%$ were university graduates, and $9.7 \%$ had postgraduate training. Of the fathers, $2.9 \%$ completed to Grades 7 to $9,17.5 \%$ completed Grades 10 to $11,15.9 \%$ completed secondary school, $44.9 \%$ had partial college/specialised training, $15.9 \%$ were university graduates, and $2.9 \%$ had postgraduate training. The mode occupational status for mothers was professional (45\%) and for fathers was trades-person and related workers (35\%).

\section{Measures}

Letter name and sound knowledge. Children were presented with the 26 alphabet letters printed in upper-case black Century Gothic font size 72 on individual 8 x $8 \mathrm{~cm}$ white cards in random order. They were asked the letter name and sound of each letter (score of one point each). Test-retest reliability was .91 from pre- to post-test and .90 from pre- to followup. From post-test to follow-up, the test-retest reliability was .97.

Letter writing. Children were asked to write all the letters they could in 60 seconds. If children stopped early they were prompted to write more. Each letter written correctly scored 1 point, repeated letters were counted only once, and upper and lower case letters were given 1 point each (e.g., B and b). Gentry’s (2005) writing samples and descriptions were used to determine correctness of letters. Test-retest reliabilities for pre-test to post-test and follow-up were .41, and from post-test to follow-up was .93.

Print concepts. (Clay, 2005). Ten items suitable for non-reading children of the target age range were selected from this 24-item test that assesses children's awareness and knowledge about print. Selected items focused on book handling (e.g., where to start reading) 
and concepts of letter and word. The items were administered in the context of the examiner reading a storybook (Sand; Clay, 2008) to the child. Children scored 1 for each correct response. The 24-item test has an acceptable split half reliability (.84 to .89) and validity (.64 to .79; Brassard \& Boehm, 2007). For 10 items used in this study, split-half reliabilities (Spearman-Brown) were .66 at pre-test and .73 at post-test and follow-up.

Environmental print reading. The design and scoring for this measure was similar to that used in previous environmental print studies (Blair \& Savage, 2006; Lomax \& McGee, 1987). Ten environmental print words were selected based on those that were common in the local area (MILO, EXIT, FROOT LOOPS, LEGO, CORN FLAKES, SUBWAY, RICE BUBBLES, STOP, NUTRI-GRAIN, PEPSI). They were randomly presented in full context (e.g., on a cereal box). The examiner ran her finger under the target word in the label/logo, asking, "What does this say?" Children scored 1 for each correct response. Test-retest reliabilities from pre-test to post-test and follow-up were .65 and .70, respectively, and from post-test to follow-up was .89.

Standard print reading. The same 10 environmental print words were printed in black Century Gothic font size 120 on 10 x $20 \mathrm{~cm}$ white card. The procedure was the same as for the environmental print reading. Test-retest reliability from post-test to follow-up was .43 (there were zero variance problems at pre-test so this was not usable).

Print motivation. Three items from Baker and Scher's (2002) Motivations for Reading Scale assessed motivation for storybook reading (likes/dislikes when someone reads them a book; likes/dislikes to read books by themself; thinks reading is boring/fun). An additional three items each were developed for this study to assess motivation for writing (e.g., likes/dislikes to do writing; likes/dislikes when someone helps them write; thinks writing is boring/fun) and environmental print reading (likes/dislikes to read signs e.g., a stop 
sign; likes/dislikes to read letters and words on boxes; thinks reading signs is boring/fun). Two filler items (likes/dislikes brushing their teeth; likes/dislikes eating broccoli) were also included. We used Baker and Scher's (2002) puppet procedure. One puppet portrayed a positive attitude to the literacy activity and the other a negative view (e.g., "Harry likes to read books by himself. Larry does not like to read books by himself'). The child was asked who they are most like (“Are you more like Harry or Larry?”) and then whether they were "a little" or "a lot" like the puppet selected. This provided a 4-point motivation response format $(1=$ dislikes a lot, 2 =dislikes a little, 3 = likes a little, $4=$ likes a lot $)$. Test-retest reliability was .33 from pre- to post-test, .42 from pre-test to follow-up, and .60 from post-test to follow-up.

Peabody Picture Vocabulary Test $4^{\text {th }}$ Edition (PPVT-IV; Dunn \& Dunn, 2007). This measures receptive vocabulary, which was included as an initial screening measure as well as a control. The PPVT-IV is normed for 2.5 to over 90 years of age. Children select one of four pictures that best represents a word spoken by the examiner. Dunn and Dunn (2007) reported split-half reliabilities of around .94 .

\section{Procedure}

Ethical clearance was granted by the university ethics committee. The study was advertised to parents of children aged between 3.5 and 4.5 years at four different preschools in the Gold Coast area. Four children for whom parents provided consent did not participate (two were excluded due to speech and hearing problems, one left their preschool prior to the intervention, and one withdrew prior to the intervention). There was no attrition of participants during the intervention or at post or follow-up test times. Consenting parents completed a questionnaire regarding demographic details. Following this, pre-tests of emergent literacy and print motivation were administered to the children over a 2 -week 
period immediately before the intervention. Receptive vocabulary was also assessed at this time. Testing took approximately 30 minutes and was conducted by the first author in a quiet room at each of the children's preschool.

Children at each preschool were randomly assigned to environmental print $(n=25 ; 12$ boys, 13 girls), standard print ( $n=23 ; 13$ boys, 10 girls), or no intervention control $(n=25$; 12 boys, 13 girls) groups. The intervention groups were further broken down into instructional groups of 4 to 5 children each. The mean ages were: environmental print $=4.2$ years $(S D=0.20)$, standard print $=4.1$ years $(S D=0.26)$, and control group 4.0 years $(S D=$ 0.25). The first author (an experienced teacher not connected with the participating preschools) conducted the two intervention programs. Interventions were 30 minutes per week for 8 weeks. Instructional groups were taken out of their classrooms to a quiet room. Each session was videotaped so that treatment fidelity and program adherence could be checked. Children's attendance was recorded. During this 8-week period, the no intervention control group received their regular play-based program. Post-tests on the emergent literacy and print motivation battery were conducted over a 2 -week period immediately following the intervention (post-test) and again 2 months later (follow-up test).

\section{Intervention Program}

The intervention program and the letters taught were identical in both the environmental print and standard print groups. Environmental print products were used for the environmental print group, whereas for the standard print group the same environmental print words were printed in black upper-case century gothic font size 120 on 10 x $20 \mathrm{~cm}$ on white card. The focal letters taught in order were M, I, O, F, T, P, C, L, S, R, E, B, N, G, and A. In the environmental print group, these were taught from product labels and signs commonly found in the children's local surroundings (MILO, FROOT LOOPS, CORN 
FLAKES, RICE BUBBLES, NUTRI-GRAIN, EXIT, LEGO, SUBWAY, STOP, PICNIC, MILK, PEPSI, COCO POPS, SMITHS, SNICKERS, VEGEMITE, HEINZ, POP TOPS, SUNBEAM, ARNOTT'S, UNCLE TOBYS, JUST JUICE, BERRI, SAMBOY, SOLO, KRAFT). In the standard print program, these same words were used but printed in black manuscript form on white card. The environmental print program will be explained in detail; however, the procedures were identical for the standard print group with the except for the form in which words were presented.

\section{Environmental Print Program}

Appendix A describes the activities in detail. In the first 5 weeks, three new letters were introduced per week. In Week 1, Activity 1 involved introducing cereal boxes and grocery products that contained the target letters for each week to the children. Activity 2 consisted of singing with actions to learn directional terms up, down, around, and across (Neumann, 2007), which was used to scaffold children's letter shaping when forming letters in the air, tracing them with fingers, and writing them on paper. Activity 3 focussed on identifying the letters embedded in the words. It used a multisensory strategy in which children interacted with each letter using their four senses; Look and Point (visual, point to the M in MILO), Say the letter name and sound (auditory; e.g., "M for MILO makes a /m/ sound”), Move (kinaesthetic, e.g., "M for MILO goes up, down, up, down - move your arm up and down in the sky), and Trace (tactile; trace the shape of the letter with a finger saying "up, down, up, down"). Each child had three turns at tracing each target letter on the products. In Activity 4, the instructor pointed out the target letters in other environmental print using the 'point, say, move, trace' method and encouraged children to find these letters (e.g., M in MILK, VEGEMITE, and SUNBEAM). Activity 5 was the letter writing activity. The instructor referred to the letters on a product (e.g., M in MILO) then modelled writing each target letter on an upright magnetic sketch board using directional language while 
referring to the letter name and sound (e.g., " its' name is $m$, it makes a $/ \mathrm{m} /$ sound, and goes up, down, up, down”). The children wrote the letter in the sky using directional language before writing it in their book with a pencil.

In Weeks 2 to 5, Activity 1 involved revising all the letters learnt in the previous weeks, with each child identifying each letter once using the point, say, move, and trace method. In weeks 6 to 8, each revision session commenced with singing (Activity 2) followed by revision of the 15 letters using the multisensory method to find and identify letters, and then the writing activity (Activity 5).

\section{Program Fidelity}

To determine instructor fidelity and program adherence across the two interventions, each session was videotaped using a camera placed at the rear of the room. Sixteen sessions ( $20 \%$ of the total) were selected in a stratified random method so that two sessions were randomly sampled from each week from each type of intervention. An experienced research assistant blind to the study's design and hypotheses rated fidelity based on similar criteria to that used by Hamre et al. (2010) and Webster-Stratton, Reid, and Stoolmiller (2008). Hamre et al. (2010) used a simple checklist score of present (1) or absent (0). To increase the sensitivity of this measure, we used a 4 -point rating scale $(1=$ never, $2=$ sometimes, $3=$ mostly, 4=always) to score the instructor's behaviour. The sessions were scored on (1) the number of positive reinforcements given (e.g., good job, yes!), (2) 10 items regarding the instructor behaviour during the session (e.g., uses clear and concise age-appropriate language) and (3) 4 items regarding program adherence (e.g., instructor's language is in accordance with the program script; see Appendix B for the fidelity criteria). Independent samples $t$-tests showed no significant differences between the environmental print and standard print conditions on any of these items (all $p \mathrm{~s}>.05$ ). 


\section{Results}

\section{Preliminary Analyses}

Table 1 shows the descriptive statistics for children's pre-test, post-test, and 2-month follow-up scores. There was some positive skew in letter name knowledge at pre-test but this variable was normally distributed at post-test and follow-up. Letter sound knowledge and letter writing were significantly positively skewed at all three test times. Square root transformation was applied to normalise these distributions. At pre-test, only 2 children (both in the environmental print group) could read 1 word in standard print; the remainder could not read any. Therefore, this measure could not be used at pre-test. At post-test and followup, standard word reading was significantly positively skewed; however, log transformations normalised these distributions. All other variables were normally distributed.

Preliminary analyses showed that the three groups (environmental print, standard print, and control) did not differ significantly at pre-test on gender $\chi^{2}(2, N=73)=0.46, p=$ $.80 ;$ age $F(2,70)=2.87, p=.06 ; \operatorname{SES} F(2,70)=.05, p=.96 ;$ receptive vocabulary $F(2,70)$ $=.81, p=.45$; letter name knowledge $F(2,70)=1.39, p=.26$; letter sound knowledge, $F(2$, $70)=0.93, p=.40 ;$ print concepts $F(2,70)=.37, p=.69$; environmental print reading $F(2$, $70)=2.92, p=.061$; or print motivation $F(2,70)=1.18, p=.31$. There was a significant difference between groups at pre-test on letter writing, $F(2,70)=3.21, p=.046$. As Table 1 shows, the environmental print group could write significantly more letters than the standard print group, $p=.02$, but did not differ from the control group, $p=.061$. The standard print and control groups did not differ significantly in letter writing at pre-test, $p=.60$. Attendance did not differ between the two intervention groups, $t(46)=0.02, p=.98$. Attendance was high in both the environmental print $(M=7.08 ; S D=1.15)$ and the standard print $(M=7.09$, $S D=1.08)$ groups 
Correlations among measures at each phase are presented in Table 2. The strongest correlations were between letter name and sound knowledge, letter writing, and print concepts at each phase. The almost perfect correlation between letter name knowledge across the three phases indicates strong stability in the growth rate of those scores over time. The strength of the correlations between environmental print and standard print reading increased over time, as did the strength of the correlations between these and the measures of letter knowledge and print concepts, especially for environmental print reading. 
Table 1

Descriptive Statistics: Means (Standard Deviations, Range)

\begin{tabular}{|c|c|c|c|c|c|c|c|c|c|}
\hline \multirow[b]{2}{*}{ Variable } & \multirow{2}{*}{\multicolumn{2}{|c|}{$\begin{array}{l}\text { Pre-test } \\
\text { SP }\end{array}$}} & \multirow[b]{2}{*}{ Control } & \multirow{2}{*}{\multicolumn{2}{|c|}{$\begin{array}{l}\text { Post-test } \\
\text { SP }\end{array}$}} & \multirow[b]{2}{*}{ Control } & \multicolumn{3}{|c|}{ Follow-up test } \\
\hline & & & & & & & EP & $\mathrm{SP}$ & Control \\
\hline Letter name $^{\mathrm{a}}$ & $6.08(7.40,0-23)$ & $3.74(3.93,0-12)$ & $6.60(6.81,0-22)$ & $\begin{array}{l}10.88(9.16,0- \\
26)\end{array}$ & $\begin{array}{l}6.83(6.43,0- \\
19)\end{array}$ & $\begin{array}{l}9.12(9.24,0- \\
25)\end{array}$ & $\begin{array}{l}11.96(9.38,0- \\
26)\end{array}$ & $\begin{array}{l}8.43(7.29,0- \\
24)\end{array}$ & $9.96(9.54,0-26)$ \\
\hline Letter sound ${ }^{\mathrm{b}}$ & $0.32(0.58,0-2)$ & $0.87(1.29,0-4)$ & $1.04(2.05,0-7)$ & $\begin{array}{l}6.48(5.32,1- \\
17)\end{array}$ & $\begin{array}{l}4.87(4.75,0- \\
16)\end{array}$ & $\begin{array}{l}2.32(3.44,0- \\
12)\end{array}$ & $\begin{array}{l}7.16(6.50,0- \\
20)\end{array}$ & $\begin{array}{l}5.17(4.78,0- \\
15)\end{array}$ & $2.84(3.91,0-11)$ \\
\hline Letter writing & $2.00(2.02,0-7)$ & $1.00(1.71,0-6)$ & $1.08(1.22,0-4)$ & $\begin{array}{l}4.36(2.68,0- \\
14)\end{array}$ & $\begin{array}{l}3.61(2.50,0- \\
10)\end{array}$ & $2.08(1.78,0-6)$ & $5.12(2.17,2-9)$ & $\begin{array}{l}3.17(2.74,0- \\
10)\end{array}$ & $1.96(2.25,0-7)$ \\
\hline Print concepts ${ }^{\mathrm{c}}$ & $4.92(1.58,1-8)$ & $5.00(2.0,2-9)$ & $5.36(2.12,2-10)$ & $6.80(1.80,4-9)$ & $6.43(1.70,4-9)$ & $\begin{array}{l}5.32(2.19,3- \\
10)\end{array}$ & $\begin{array}{l}6.64(2.33,2- \\
10)\end{array}$ & $5.87(2.51,2-9)$ & $5.20(2.06,2-9)$ \\
\hline EP word reading ${ }^{d}$ & $2.16(1.31,0-5)$ & $1.3(1.14,0-4)$ & $1.56(1.32,0-5)$ & $6.12(2.33,1-9)$ & $2.3(1.58,0-5)$ & $1.92(1.52,0-6)$ & $5.28(2.59,0-9)$ & $2.61(1.47,0-5)$ & $2.32(1.43,0-5)$ \\
\hline SP word reading ${ }^{\mathrm{e}}$ & $0.08(0.28,0-1)$ & $0.00(0.00,0-0)$ & $0.00(0.00,0-0)$ & $0.68(0.95,0-3)$ & $0.87(0.92,0-3)$ & $0.00(0.00,0-0)$ & $0.68(0.99,0-3)$ & $0.22(0.52,0-2)$ & $0.12(0.33,0-1)$ \\
\hline Print motivation ${ }^{\mathrm{f}}$ & $28.16(5.14,18-36)$ & $26.39(4.37,18-35)$ & $28.44(5.29,14-36)$ & $\begin{array}{l}30.60(3.89,23- \\
36)\end{array}$ & $\begin{array}{l}27.78(4.52,20- \\
36)\end{array}$ & $\begin{array}{l}27.16(1.14,18- \\
36)\end{array}$ & $\begin{array}{l}30.60(3.73,22- \\
36)\end{array}$ & $\begin{array}{l}24.39(5.46,12- \\
36)\end{array}$ & $25.08(4.88,18-36)$ \\
\hline
\end{tabular}

Note EP $=$ Environmental print group SP $=$ Standard print group C $=$ Control group; Pre-test $=$ immediately before intervention; Post-test $=$ immediately after intervention; Follow-up test $=8$ weeks after intervention

Maximum test score: ${ }^{\mathrm{a}}=26 ;^{\mathrm{b}}=26 ;^{\mathrm{c}}=10 ;{ }^{\mathrm{d}}=10 ;{ }^{\mathrm{e}}=10 ;{ }^{\mathrm{f}}=36$. 
Table 2 Correlations among screening, pre-test, post-test, and follow-up measures Notes: $\mathrm{T} 1=$ pre-test, $\mathrm{T} 2=$ post-test, $\mathrm{T} 3=$ follow-up. $\mathrm{EP}=\mathrm{Environmental}$ print, $\mathrm{SP}=\mathrm{Standard}$ print. $* p<.05$, ** $p<.01$

\begin{tabular}{|c|c|c|c|c|c|c|c|c|c|c|c|c|c|c|c|c|c|c|c|c|c|c|}
\hline & 2 & 3 & 4 & 5 & 6 & 7 & 8 & 9 & 10 & 11 & 12 & 13 & 14 & 15 & 16 & 17 & 18 & 19 & 20 & 21 & 22 & 23 \\
\hline 1. T1Age (years) & $.51^{\circ}$ & .11 & .14 & $.42^{* 2}$ & .12 & .18 & -.03 & -.15 & .11 & $.30^{2}$ & .36 & $.24^{2}$ & $.24^{2}$ & .16 & -.14 & .12 & $.28^{*}$ & $.33^{3 \prime}$ & .15 & .18 & -.07 & -.13 \\
\hline 2. T1 Vocabulary & & $.25^{*}$ & $.37^{* *}$ & $.43^{* *}$ & $.31^{* *}$ & $.25^{\circ}$ & .03 & -.02 & $.31^{* *}$ & $.45^{* *}$ & . $48^{* *+}$ & $.46^{* *}$ & $.34^{* *}$ & .18 & -.02 & $.33^{* *}$ & $.40^{* *}$ & $.44^{* *}$ & $.37^{* *}$ & $.36^{* *}$ & .16 & .06 \\
\hline 3. T1 Letter name & & - & $.50^{* *}$ & $.32^{* *}$ & $.55^{* *}$ & .14 & .21 & .14 & $.91^{* *}$ & $.61^{* * *}$ & $.30^{*}$ & $.49^{* *}$ & .17 & .16 & .22 & $.90^{* *}$ & $.66^{* *}$ & $.27^{*}$ & $.38^{* *}$ & $.30^{*}$ & $.27^{*}$ & .22 \\
\hline 4. T1 Letter sound & & & - & $.26^{*}$ & $.38^{* *}$ & .11 & -.03 & .01 & $.43^{* *}$ & $.41^{* * *}$ & $.27^{*}$ & $.46^{* *}$ & -.02 & .09 & -.03 & $.43^{* *}$ & $.41^{* *}$ & .20 & $.33^{* *}$ & .08 & .02 & -.05 \\
\hline 5. T1 Letter writing & & & & - & $.25^{\circ}$ & .17 & .11 & .10 & $.35^{* *}$ & $.47^{* *}$ & $.65^{* *}$ & $.38^{* *}$ & $.26^{\circ}$ & .19 & -.13 & $.36^{*}$ & $.41^{* *}$ & $.57^{* *}$ & $.33^{* *}$ & $.35^{* *}$ & $.31^{* *}$ & .03 \\
\hline 6. T1 Print concepts & & & & & - & .14 & .08 & .05 & $.53^{* *}$ & $.40^{* * *}$ & .16 & $.41^{* * *}$ & .05 & .09 & .12 & $.51^{* *}$ & $.34^{* *}$ & .16 & $.41^{* *}$ & .10 & .20 & .11 \\
\hline 7. T1 EP reading & & & & & & - & $.24^{*}$ & $-.26^{*}$ & .17 & .20 & .08 & $.24^{*}$ & $.65^{* *}$ & .20 & -.06 & .21 & $.27^{*}$ & .20 & .15 & $.70^{* * *}$ & .12 & -.01 \\
\hline 8. T1 SP reading & & & & & & & - & .04 & .18 & .00 & .08 & .11 & $.29^{*}$ & $.40^{* *}$ & .17 & .19 & .06 & .01 & .08 & $.37^{* *}$ & $.28^{*}$ & .17 \\
\hline 9. T1 Print motivation & & & & & & & & - & .15 & .20 & .13 & .05 & -.08 & -.12 & $.33^{* *}$ & .14 & .12 & -.10 & .01 & .00 & .12 & $.42^{* *}$ \\
\hline 10. T2 Letter name & & & & & & & & & - & $.71^{* * *}$ & $.36^{* \prime}$ & $.55^{* *}$ & $.26^{*}$ & .18 & $.28^{*}$ & $.97^{* *}$ & $.75^{* *}$ & $.42^{* *}$ & $.50^{* *}$ & $.38^{* *}$ & $.30^{*}$ & $.26^{*}$ \\
\hline 11. T2 Letter sound & & & & & & & & & & - & $.57^{* *+}$ & $.69^{* *}$ & $.37^{* *}$ & .21 & .17 & $.70^{* *}$ & $.93^{* \prime}$ & $.59^{* *}$ & $.63^{* \prime}$ & $.45^{* *}$ & $.31^{*}$ & .23 \\
\hline 12. T2 Letter writing & & & & & & & & & & & - & $.46^{* \prime}$ & .23 & .20 & .03 & $.35^{* \prime}$ & $.51^{* \prime}$ & $.70^{* *}$ & $.40^{* *}$ & $.31^{* \prime}$ & $.30^{*}$ & .06 \\
\hline 13. T2 Print concepts & & & & & & & & & & & & - & $.31^{* *}$ & $.30^{*}$ & .15 & $.61^{* *}$ & $.61^{* *}$ & $.44^{* *}$ & $.71^{* *}$ & $.38^{* *}$ & $.36^{* 2}$ & .21 \\
\hline 14. T2 EP reading & & & & & & & & & & & & & - & $.33^{* *}$ & .22 & $.27^{*}$ & $.41^{* *}$ & $.37^{* *}$ & $.29^{*}$ & $.89^{* *}$ & $.39^{* *}$ & .21 \\
\hline 15. T2 SP reading & & & & & & & & & & & & & & - & .11 & $.27^{*}$ & $.28^{*}$ & .19 & .19 & $.37^{* *}$ & $.43^{* *}$ & .03 \\
\hline 16. T2 Print motivation & & & & & & & & & & & & & & & - & $.29^{*}$ & .18 & -.01 & .13 & .15 & .14 & $.60^{* *}$ \\
\hline 17. T3 Letter name & & & & & & & & & & & & & & & & - & $.76^{* *}$ & $.44^{* *}$ & $.56^{* *}$ & $.41^{* *}$ & $.35^{* *}$ & $.28^{*}$ \\
\hline 18. T3 Letter sound & & & & & & & & & & & & & & & & & - & $.62^{* *}$ & $.56^{* *}$ & $.52^{* *}$ & $.32^{* *}$ & .21 \\
\hline 19. T3 Letter writing & & & & & & & & & & & & & & & & & & - & $.39^{* *}$ & $.48^{* *}$ & $.33^{* *}$ & .60 \\
\hline 20. T3 Print concepts & & & & & & & & & & & & & & & & & & & - & $.26^{*}$ & $.29^{*}$ & .17 \\
\hline 21. T3 EP reading & & & & & & & & & & & & & & & & & & & & - & $.51^{* *}$ & .17 \\
\hline 22. T3 SP reading & & & & & & & & & & & & & & & & & & & & & - & $.24^{*}$ \\
\hline 23. T3 Print motivation & & & & & & & & & & & & & & & & & & & & & & - \\
\hline
\end{tabular}




\section{Intervention Effects}

Based on the significant correlations between vocabulary and most outcome measures, vocabulary was included as a covariate in all subsequent analyses. Pre-test letter writing was also included as a covariate for analyses with letter writing as the dependent variable to control for the differences found at pre-test. Multivariate analysis of covariance (MANCOVA) was used to examine the overall effects of group on letter name and sound knowledge, letter writing, and print concepts due to the significant correlations between these emergent literacy measures. As repeated measures variables cannot be included in a MANCOVA, separate analyses were conducted on scores for post-test and follow-up (pretest was not re-examined as group effects were already analysed using the univariate tests). As the reading measures and print motivation were not correlated with these letter knowledge measures, they were not included in the MANCOVAs but were analysed separately in ANCOVAs with vocabulary as the covariate.

Letter knowledge and print concepts. A MANCOVA with letter name and sound knowledge, letter writing and print concepts as dependent variables and vocabulary as the covariate was conducted separately for post-test and follow-up. Due to violation of the assumption of homogeneity of variance for letter name knowledge, Pillai's trace was interpreted because it is more robust to those violations than Wilk's lambda. Vocabulary was a significant covariate in all analyses. At post-test, with effects of vocabulary controlled, there was a significant multivariate effect for group, $F(8,134)=3.41, p=.001, \eta_{\mathrm{p}}{ }^{2}=.17$. Univariate tests and pairwise comparisons were used to interpret this overall effect.

At post-test univariate tests indicated a significant effect for group on letter sound knowledge, $F(2,69)=6.56, p=.002, \eta_{\mathrm{p}}{ }^{2}=.16$. Pairwise comparisons showed that this was due to significantly higher letter sound knowledge in the environmental print group than the 
control group, $p=.001, d=0.71$, and in the standard print group compared to the control group, $p=.017, d=0.50$. The two intervention groups did not differ significantly.

There was also a significant univariate effect for letter writing at post-test, $F(2,69)=$ 4.76, $p=.012, \eta_{\mathrm{p}}{ }^{2}=.12$. Pairwise comparisons showed that this was due to significantly higher letter writing in the environmental print and standard print groups than the control group, $p=.004, d=0.59$ and $p=.027, d=0.46$, respectively. The two intervention groups did not differ significantly. At pre-test there had been a significant difference in letter writing such that the environmental print group scored higher than the control group. There was also a trend toward that group scoring higher than the standard print group. To account for these initial differences, a further univariate ANCOVA with both vocabulary and pre-test letter writing included as covariates was conducted. Both were significant covariates. There was a significant overall effect for group, $F(2,68)=5.98, p=.004, \eta_{\mathrm{p}}{ }^{2}=.15$. Pairwise comparisons indicated similar results to those without pre-letter writing controlled. The environmental print and standard print groups both performed better than the control group, $p=.009, d=$ 0.54 and $p=.002, d=0.65$, respectively, but did not differ from each other, $p=.60$.

There was no overall significant univariate effect for letter name knowledge at posttest, $F(2,69)=0.68, p=.51$. There was also no significant univariate effect for print concepts, $F(2,69)=2.90, p=.11$. However, pairwise comparisons showed that the environmental print group scored significantly higher on print concepts than did the control group, $p=.043, d=0.41$. No other group differences were significant.

At 2-month follow-up, the assumption of homogeneity of variance was violated for letter name knowledge and letter writing and the assumption of equality of covariance matrices was not met. Therefore, Pillai's trace was used. There was an overall multivariate 
effect for group on letter knowledge, after controlling for the effects of vocabulary, $F(8,134)$ $=3.99, p<.001, \eta_{\mathrm{p}}^{2}=.19$.

There was a significant univariate effect for group on letter sound knowledge at follow-up, $F(2,69)=3.60, p=.033, \eta_{\mathrm{p}}{ }^{2}=.09$. Pairwise comparisons showed that this was due to significantly higher letter sound knowledge in the environmental print group than the control group, $p=.01, d=0.53$. The standard print group no longer differed significantly from the control group or environmental print group at the 2-month follow-up.

There was also a significant univariate effect for group on letter writing at follow-up, $F(2,69)=5.90, p<.001, \eta_{\mathrm{p}}{ }^{2}=.24$. Pairwise comparisons showed that this was due to significantly higher letter writing in the environmental print than the standard print, $p=.006$, $d=0.58$, and control, $p<.001, d=0.93$, groups. The standard print and control groups did not differ significantly. Because there had been some significant group differences in letter writing at pre-test, an additional univariate ANCOVA was conducted with both vocabulary and pre-test letter writing included as covariates. Results showed a significant univariate effect for group, $F(2,68)=9.80, p<.001, \eta_{\mathrm{p}}^{2}=.22$. With pre-test letter writing also controlled, pairwise comparisons indicated that the environmental group scored higher at follow-up than both the standard print group and the control group, $p<.001, d=0.42$, and $p$ $=.043, d=0.89$, respectively. In addition, once pre-test scores were controlled, the standard print group also scored significantly higher than the control group, $p=.026, d=0.47$.

Similarly to the results at post-test, there were no significant univariate effect for group on letter name knowledge, $F(2,69)=0.40, p=.67$, or print concepts, $F(2,69)=1.35$, $p=.27$. Unlike the result at post-test, no pairwise differences in print concepts were found at the two-month follow-up. 
Environmental print reading. Univariate ANCOVAs were performed with vocabulary and pre-test environmental print reading as the covariates and environmental print reading at post-test and at follow-up as the dependent variables. Pre-test environmental print reading was also included as a covariate because although the groups did not differ significantly at pre-test, there was a marginal trend toward a group difference. Thus, including the pre-test provided a more stringent test of the effects of the intervention. Only the pre-test environmental print reading was a significant covariate. The effects of vocabulary failed to reach significance, $p=.075$.

At post-test, there was a significant group effect $F(2,68)=45.61, p<.001, \eta_{\mathrm{p}}{ }^{2}=.57$. Pairwise comparisons showed that, with pre-test environmental print reading controlled, the environmental print group read significantly more environmental print words at post-test than the standard print $(d=1.52)$ and control $(d=1.79)$ groups, $p<.001$. The standard print and control groups did not differ.

At follow-up test, results were similar. There was a significant overall effect from group, $F(2,68)=16.82, p<.001, \eta^{2}=.33$. The environmental print group scored significantly higher than the standard print $(d=0.89)$ and control $(d=1.10)$ groups, $p<.001$. The standard print and control group did not differ significantly, $p=.30$.

Standard print reading. Univariate ANCOVAs were performed using log transformed standard print reading scores at post-test and follow-up as the dependent variables and vocabulary as the covariate. Vocabulary was not a significant covariate at either testing phase. At post-test, there was a significant effect for group, $F(2,69)=9.30, p<.001$, $\eta^{2}=.21$. The two intervention groups did not differ significantly, $p=.275$. However, the environmental print group could read more standard print words than the control group, $p<$ $.001, d=0.62$, as could the standard print group, $p=.003, d=0.84$. 
At follow-up testing, there was a significant effect for group, $F(2,69)=3.88, p=$ $.025, \eta^{2}=.10$. By follow-up, the environmental print group could read more standard print words than the standard print, $p=.031, d=0.45$ and control, $p=.012, d=0.51$, groups. However, the standard print group no longer differed from the control group, $p=.72$.

Print motivation. A univariate ANCOVA, with vocabulary as the covariate, was conducted to determine the effects of group on print motivation at post-test and follow-up. However, vocabulary was not a significant covariate. There was a significant effect for group on print motivation at post-test, $F(2,69)=3.86, p=.026, \eta_{\mathrm{p}}{ }^{2}=.10$. Pairwise comparisons showed that the environmental print group had significantly higher print motivation than the standard print, $p=.042, d=0.42$, and control, $p=.011, d=0.53$, groups at post-test. The standard print and control groups did not differ, $p=.58$.

At follow-up test, there was a significant overall group effect, $F(2,69)=12.27, p<$ $.001, \eta^{2}=.26$. Pairwise comparisons revealed a similar pattern of differences to those found at post-test. The standard print and control groups did not differ significantly, $p=.62$. However, the environmental print group showed higher motivation than both the standard print and control groups, $p<.001, d=0.92$ and 0.80 , respectively.

\section{Discussion}

This paper reports a randomised, controlled intervention study that evaluated the effects of using environmental print in context compared to standard print (the same labels in manuscript form) and a no intervention control on young children's emergent literacy skills and print motivation. Environmental print was expected to be more effective due to its engaging colours and familiarity and because it affords children the opportunity for learning experiences virtually everywhere given its ubiquitous nature. Results showed that children who were instructed with environmental print showed higher print motivation both at 
completion of the intervention and 2 months later than children who were instructed with the same words in manuscript form or who had no intervention. They also recognised more environmental print words than these other two groups at both times. Immediately following training, both intervention groups performed better than the control group on letter writing and standard print reading. However, by the 2-month follow-up, the environmental print group performed better than both of these other groups on letter writing and standard print reading, but there were no longer any differences in print concepts between the groups. The environmental print group performed equivalently to the standard print group on letter sound knowledge and better than the control group at post and follow-up. No group differences were found in letter name knowledge at either time.

Moderate to large effects were obtained while controlling for differences in children's receptive language abilities and, where needed, differences at pre-test. This represents a stringent test of the effects of these interventions on emergent literacy. These results support previous research showing that intervention using environmental print benefits emergent literacy (Prior, 2003; Salewski, 1995; Vera, 2007; Wepner, 1985). However, the present study extended that previous work, using a more rigorous randomised control design and examining the effects of environmental print on a broader range of emergent literacy skills, while controlling for potential confounding factors. In particular, the standard print comparison group allowed us to ascertain whether the colourful unique appearance of environmental print helped or hindered young children's learning of print. The fact that there were many advantages for the environmental print group over the standard print group indicates that using environmental print helps foster and sustains emergent literacy growth.

The environmental print group showed significantly higher print motivation postintervention than the other two groups. Previous studies had not examined this. It seems reasonable to argue that the colourful and attractive nature of environmental print was 
responsible for this advantage. This is consistent with Wepner's (1985) assertion that the attention-grabbing nature of environmental print benefits children's interest in print.

Encouraging children to interact with environmental print may have motivated them to seek it out on occasion in their broader contexts; for example, when grocery shopping with parents or travelling in the car. During the environmental print training sessions, it was observed that environmental print provided opportunities for children to initiate discussions with the instructor and each other during the sessions. Children shared experiences where they had found target letters from the previous week's session at the grocery store or at breakfast time. Children also pointed out letters other than the training letters on products during the sessions (e.g., the $\mathrm{K}$ in CORNFLAKES). They also referred to and asked questions about letters and words on signs and posters as they walked back to their classrooms after each session. In contrast, these types of interactions were not observed in the standard print group. Although this evidence is anecdotal, it suggests that children's guided attention to environmental print letters during the sessions was transferred to environmental print they discovered outside the session. Print motivation prior to school entry is likely to influence how a child approaches formal literacy activities, specifically, their reading motivation, which, in turn, influences their future literacy skills (Baker et al., 1997). Therefore, using environmental print to foster this motivation is likely to have long-term literacy benefits beyond the 2-month period examined in this study.

The present study also extended current knowledge on the effects of environmental print instruction on early writing. While both the standard print and environmental print groups wrote more letters post-intervention than the control group, 2 months later the environmental print group wrote significantly more than the both these other groups. This indicates that environmental print is an effective tool for supporting letter writing in young children. Although speculative, it is possible that the sustained effects seen in the 
environmental print group reflected children's ability to access letters in environmental print during their daily lives to assist their ongoing attempts at letter writing. These results also provide empirical support for case studies that describe young children using environmental print words and letters to help them write (Chan et al., 2008; Neumann, Hood, \& Neumann, 2009; Neumann \& Neumann, 2010).

The environmental print and standard print group outperformed the control group on letter sound knowledge at post-test. Therefore, training children using print in context with logos produced similar gains to using print in black and white manuscript form. This suggests that using environmental print with or without contextual cues can benefit letter sound learning. Prior (2003) also found that kindergarten children from lower SES schools made significant post-test gains in letter sound knowledge following environmental print instruction. However, our follow-up findings showed that using environmental print, not standard print, sustained letter sound gains over the control group. This suggests that the environmental print with its contextual cues may provide longer term benefits to letter sound learning as children seek out logos in their broader surroundings at preschool and at home.

Unexpectedly, we found no group differences on letter name knowledge. To address this issue, we further examined whether the groups differed on letter name knowledge for the 15 letters specifically taught during the intervention. With the effects of vocabulary controlled, there was no overall group effect at post-test. However, the pairwise comparisons showed that the environmental print group knew significantly more of the trained letters $(M=$ $6.44, S D=4.07)$ than the control group $(M=3.40, S D=3.19), p=.02$, but not the standard print group $(M=4.65, S D=3.19), p=.09$. At follow-up, there was also no overall group effect. However, this time the environmental print group $(M=6.40, S D=4.17)$ outperformed the standard print group $(M=4.17, S D=3.2), p=.026$, although not the control group $(M=$ $4.00, S D=3.54), p=.062$. These results suggest that there were some gains in letter name 
knowledge for the environmental print group on the trained letters, with this gain being maintained over the long term. This is consistent with Lomax and McGee (1987) who showed that environmental print knowledge was related to letter naming. However, this gain did not generalise to improvements in broader letter name knowledge, thus highlighting the importance of specific training on letters. In contrast, the standard print group failed to differ from the control group at either testing time, and scored significantly lower than the environmental print group at the 2-month follow-up. Again we can only speculate, but this suggests that there are additional advantages to using environmental print for letter name acquisition and retention.

For print concepts, the overall group effect did not reach significance once vocabulary was controlled. However, the environmental print group made significant gains over the control group at post-test. These results are similar to previous studies (Wepner, 1985; Vera, 2007). Thus, training with environmental print appears to foster conceptual understanding of what words and letters are, along with other print concepts relevant to this age group. We also found that the standard print group did not make significant gains over the control group. This suggests that the colours and logos in environmental print may have helped children attend to print providing added opportunities for the development of print concepts.

As expected, environmental print reading improved more in the environmental print group than in the other groups. This supports previous research showing that children's logographic reading improves following exposure to logos (Prior, 2003; Wepner, 1985). We also found that immediately following the intervention, the two intervention groups performed similarly at identifying the words in standard manuscript form. However, two months later, children trained using the environmental print identified more words in standard print form than did the standard print group. In fact, by that time the standard print group did not differ from the control group. Once again, then, the superior performance of the 
environmental print group provides evidence that the colourful visual cues of environmental print logos aided children's examination of the print itself.

These findings are in accord with Cronin et al., (1999) showing that non-reading 4- to 5-year-olds could learn environmental print words when presented in manuscript form more quickly if they could already recognize the environmental print word in context. Our results go further by showing that teaching words in logo form may translate to recognition in standard print format. While the mechanism underpinning this effect remains to be determined, it does indicate that environmental print can play an important role in early reading development when explicit instruction regarding letters and words in that print is used. However, the present findings must be interpreted cautiously as only a few children could read words in standard manuscript form at any phase in the study. These strong floor effects also account for the lower test-retest reliabilities in this measure.

The effectiveness of using environmental print to facilitate development in children's emergent literacy may depend on how it is used to scaffold children's learning. In the present study, multisensory activities were used to help children interact with letters embedded in the environmental print logos. It is possible that these activities (i.e., point, say, move, trace) contributed to the positive and sustained outcomes; for example, by improving memory or fine motor skills for linking letter shapes to sounds or physically writing letters (e.g., Moats \& Farrell, 2005). Multisensory teaching approaches have been found to benefit early literacy skill acquisition in the preschool setting (Bara, Gentaz, Cole, \& Sprenger-Charolles, 2004). Nevertheless, in the present study, this multisensory approach was also used in the standard print group, and there were still distinct advantages to using the environmental print over the standard print in conjunction with these multisensory strategies. More work is needed to examine whether using environmental print would be as effective in fostering emergent literacy without multisensory teaching. As reading already involves auditory and visual 
stimulation and integration, the question is really about the extent to which the additional tactile and kinaesthetic components contributed to the observed gains.

Although the program used in the present study was of relatively short duration, being only 30 minutes per week for 8 weeks, it yielded positive and sustained outcomes and moderate to large effect sizes indicating practical relevance. Given the greater gains for the environmental print group at follow-up, it would be worthwhile extending the duration of the program to determine if longer intervention using environmental print results in increasing gains relative to a standard print intervention. In addition, future research needs to determine the effectiveness of normal classroom teachers delivering this program. Embedding these environmental print strategies in the regular preschool classroom would enable the duration to be extended as teachers can draw children's attention to letters and words (e.g., on food product logos) during daily activities. Previous research has also shown that helping children to attend to other surrounding print that is not in logo form, such as personal names printed in and out of context, can also promote emergent literacy (Levin \& Ehri, 2009; Share \& Gur, 1999). Future research could also evaluate the effects of eye catching environmental print by comparing the gains of using research-made print versus environmental print obtained from the child's home environment.

The effectiveness of an environmental print program delivered in the home setting requires further examination as parents play a key role in supporting emergent literacy development (e.g., Hood, Conlon, \& Andrews, 2008). Using this ubiquitous and cost effective literacy resource has the potential to be implemented easily by parents from a range of SES backgrounds. Case studies have already described parents utilising environmental print to support children's literacy development (e.g., McGee \& Richgels, 1989; Neumann et al., 2009). Encouraging parents to refer to and label letters and words in a range of 
environmental print may be an effective means to promote emergent literacy and print motivation.

In conclusion, we have shown that drawing young children's attention to letters within environmental print can foster and sustain gains in a broad range of emergent literacy skills. Children were not distracted by logos but, on the contrary, the contextual cues helped children attend to print. Environmental print provided benefits over standard print such as enhancing children's print motivation, knowledge of the names of the specific letters trained, environmental print and standard print reading ability, and letter writing over the mediumterm. Improving children's motivation for print may be particularly important as this seems likely to result in further gains as children orient to and enjoy reading letters and words in surrounding print. By focusing children's attention on letters and words in environmental print, it may be possible to motivate them to initiate further independent exploration of letters in their broader surroundings, thereby increasing their learning opportunities. Future research needs to determine if similar effectiveness can be achieved with this approach by preschool teachers in the classroom as well as by parents in the home. 


\section{References}

Adams, M. J. (1990). Beginning to read: Thinking and learning about print. Cambridge, MA: MIT press.

Aram D., \& Biron, S. (2004). Joint storybook reading and joint-writing interventions among low SES preschoolers: differential contributions to early literacy. Early Childhood Research Quarterly, 19, 588-610.

Australian Government (2005). National inquiry into the teaching of literacy: Teaching reading, report and recommendations (Publication No. 064277577 X). Canberra, Australian Capital Territory: Author.

Baker, L., \& Scher, D. (2002). Beginning readers' motivation for reading in relation to parental beliefs and home reading experiences. Reading Psychology, 23, 239-269.

Baker, L., Scher, D., \& Mackler, K. (1997). Home and family influences on motivations for reading. Educational Psychologist, 32, 69-82.

Baker, L., Fernandez-Fein, S, Scher, D., \& Williams, H. (1998). Home experiences related to the development of word recognition. In J. L. Metsala \& L. C. Ehri (Eds.), Word recognition in beginning literacy (pp. 263-286). Mahwah, NJ: Lawrence Erlbaum.

Bara, F., Gentaz, E., Cole, P., \& Sprenger-Charolles, L. (2004). The visuo-haptic and haptic exploration of letters increases the kindergarten-children's understanding of the alphabetic principle. Cognitive Development, 19, 433-449.

Blair, R., \& Savage, R. (2006). Name writing but not environmental print recognition is related to letter-sound knowledge and phonological awareness in pre-readers. Reading and Writing: An Interdisciplinary Journal, 19, 991-1016. 
Bowman, M., \& Treiman, R. (2004). Stepping stones to reading. Theory into Practice, 43, 295-303.

Brassard, M. R., \& Boehm, A. E. (2007). Preschool assessment: Principles and practices. New York: Guildford Press.

Chan, L., Zi Juan, C., \& Lai Foon, C. (2008). Chinese preschool children's literacy development: From emergent to conventional writing. Early Years, 28, 135-148.

Clay, M. M. (1998). By different paths to common outcomes. York, ME: Stenhouse.

Clay, M. M. (2005). An observation survey of early literacy development. Auckland, NZ: Heinemann.

Clay, M. M. (2008). Sand. Rosedale, NZ: Pearson.

Cronin, V., Farrell, D., \& Delaney, M. (1999). Environmental print and word reading. Journal of Research in Reading, 22, 271-282.

Dunn, L. M., \& Dunn, D. M. (2007). The Peabody Picture Vocabulary Test (4 ${ }^{\text {th }}$ ed.). Bloomington, MN: NCS Pearson, Inc.

Ehri, L. C., \& Roberts, T. (2006). The roots of learning to read and write: Acquisition of letters and phonemic awareness. In S. B. Neuman \& D. K. Dickinson (Eds.), Handbook of early literacy research: Vol. 2. (pp. 113-130). New York, NY: Guildford Press.

Frith, U. (1985). Beneath the surface of developmental dyslexia. In K. Patterson, J. Marshall \& M. Coltheart (Eds.), Surface dyslexia: Neuropsychological and cognitive studies of phonological reading. (pp. 301-330). London, UK: Erlbaum. 
Gentry, J. R. (2005). Instructional techniques for emerging writers and special needs students at kindergarten and grade 1 levels. Reading and Writing Quarterly, 21, 113-134.

Goodall, M. (1984). Can four year olds "read" words in the environment? Reading Teacher, $37,478-482$.

Hamre, B. K., Justice, L. M., Pianta, R.C., Kilday, C., Sweeney, B., Downer., J. T., \& Leach., A. (2010). Implementation fidelity of My Teaching Partner literacy and language activities: Association with preschoolers' language and literacy growth. Early Childhood Research Quarterly, 25, 329-347.

Harste, J. C., Burke, C. L., \& Woodward, V. A. (1981). Examining our assumptions: A transactional view of literacy and learning. Research in the teaching of English. 18, 84-108.

Hollingshead, A. B. (1975). The four-factor index of social status: Unpublished manuscript. Yale University: New Haven, CT.

Hood, M., Conlon, E., \& Andrews, G. (2008). Preschool home literacy practices and children's literacy development: A longitudinal analysis. Journal of Educational Psychology, 100, 252-271.

Horner, S. L., (2005). Categories of environmental print: All logos are not created equal. Early Childhood Education Journal, 33, 113-119.

Justice, L. M., \& Ezell, H. K. (2001). Word and print awareness in 4-year-old children. Child and Language Teaching and Therapy, 17, 207-225.

Justice, L. M., \& Ezell, H. K. (2002). Use of storybook reading to increase print awareness in at-risk children. American Journal of Speech-Language Pathology, 11, 17-29. 
Levin, I., Shatil-Carmon, S., \& Asif-Rave, O. (2006). Learning of letter names and sounds and their contribution to word recognition, Journal of Experimental Child Psychology, 93, 139-165.

Levin, I., \& Ehri, L. C. (2009). Young children's ability to read and spell their own and classmates' names: The role of letter knowledge. Scientific Studies of Reading, 13, 249-273.

Lomax, R. G., \& McGee, L. M. (1987). Young children's concepts about print and reading: Toward a model of word reading acquisition. Reading Research Quarterly, 22, 237256.

Masonheimer, P. E., Drum, P. A., \& Ehri, L. C. (1984). Does environmental print identification lead children into word reading? Journal of Reading Behavior, 16, 257271.

McGee, L. M., \& Richgels, D. J. (1989). “K is Kristen's”: Learning the alphabet from a child's perspective. The Reading Teacher, 43, 216-225.

Moats, L. C., \& Farrell, M. L. (2005). Multisensory structured language education. In J. R. Birsch (Ed.), Multisensory teaching of basic language skills ( $2^{\text {nd }}$ ed., pp. 23-41). Baltimore, MD: Paul H. Brookes.

Neumann, M. M. (2007). Up Downs: A fun and practical way to introduce reading and writing to children aged 2-5. Sydney, Australia: Finch.

Neumann, M. M., Hood, M., \& Neumann, D. L. (2009). The scaffolding of emergent literacy skills in the home environment: A case study. Early Childhood Education Journal, 36, 313-319. 
Neumann, M. M., \& Neumann, D. L. (2010). Parental strategies to scaffold emergent writing skills in the preschool child within the home environment. Early Years: An International Journal of Research and Development, 30, 79-94.

Neumann, M. M., Hood, M., Ford, R. M., \& Neumann, D. L. (2011). The role of environmental print in emergent literacy. Journal of Early Childhood Literacy. DOI: 10.1177/1468798411417080.

Prior, J. L. (2003). Real world print in the classroom: meaningful connections for learning to read. Unpublished Doctoral Dissertation. Arizona State University, Arizona.

Ritchey, K. D. (2008). The building blocks of writing: Learning to write letters and spell words. Reading and Writing: An Interdisciplinary Journal, 21, 27-47.

Salewski, W. C. (1995). The effect of environmental print reading on the literacy development of kindergarten children. Unpublished Master's Dissertation, The University of British Columbia, Vancouver Canada. Retrieved from https://circle.ubc.ca/bitstream/2429/3660/1/ubc_1995-0145.pdf.

Share, D. L. \& Gur, T. (1999). How reading begins: A study of preschoolers' print identification strategies. Cognition and Instruction, 17, 177-213.

Snow, C. E., Burns, S., \& Griffin, P. (1998). Preventing reading difficulties in young children. Washington, DC: National Academy Press.

Teale, W. H., \& Sulzby, E. (1986). Emergent literacy as a perspective for examining how young children become readers and writers. In W. H. Teale \& E. Sulzby, (Eds.), Emergent literacy: Reading and writing (pp. 7-25). Norwood, NJ: Ablex Publishing. 
Vera, D. (2011). Using popular culture print to increase emergent literacy skills in one highpoverty urban school district. Journal of Early Childhood Literacy, 11, 307-330.

Vukelich, C., Christie, J., \& Enz, B. (2008). Helping young children learn language and literacy: Birth through kindergarten. Boston, MA: Pearson.

Webster-Stratton, C., Reid, M. J., \& Stoolmiller, M. (2008). Preventing conduct problems and improving school readiness: Evaluation of the Incredible Years Teacher and Child Training Programs in high-risk schools. The Journal of Child Psychology and Psychiatry, 49, 471-488.

Wepner, S. B. (1985). Linking logos with print for beginning reading success. Reading Teacher, 38, 633-639.

Whitehurst, G. J., \& Lonigan, C. J. (1998). Child development and emergent literacy. Child Development, 69, 848-872. 


\section{Appendix A}

\section{Intervention Program}

For the environmental print group, words were presented on grocery products (e.g., "CORN FLAKES" on the cereal box). For the standard print group the same labels were printed in manuscript form on cards. Both groups used the same weekly words and letters.

\section{Week 1 Session (Focus letters M, I, O)}

Activity 1: Introduce environmental print words.

Activity 2: Singing with actions to learn directional terms up, down, around, and across.

A) "Hands go up, hands go down, shake your hands and turn around". (Move hands then foot then leg up and down).

B) "Round and round and round and round and round go the wheels of the car". Ask what else goes round and round? (Move hands around in a circle shape).

C) Pretend your finger is a rocket ship and zoom your hand across the sky. (Move hand across the sky in a horizontal line).

D) Play the rocketship game where instructor says the words up, down, around and across as children zoom there finger according to the direction given.

Activity 3: Focus letters (M, I, O). [point, say, move, trace method]

Letter M: Present the MILO word to each child. Point to the word whilst underlining it with your finger and say MILO. Ask children to repeat the word. "Can you say this word MILO?"

The instructor models the following steps to the children (Point and Say and Move and Trace):

a) Visual: Point to the letter M and say the letter name "Its name is M"

b) Auditory: M makes a $/ \mathrm{m} /$ sound.

c) Kinaesthetic: Move your arm in the air, in the shape of the letter saying M for MILO goes up, down, up, down (write it in the sky).

d) Tactile: Trace the shape of the letter $\mathrm{M}$ with your finger saying up, down, up, down.

Now repeat steps (a) to (d) 3 times for each child. Activity 3 is repeated for the next focus letters (I, O).

Activity 4: Point out the letters M, I and O embedded in words COCO POPS, RICE BUBBLES, CORNFLAKES, PEPSI, MILO, VEGEMITE, SUNBEAM, MILK, SMITHS, LEGO, STOP, EXIT, FROOT LOOPS, NUTRIGRAIN) using the point, say, move, trace method.

Activity 5: Writing activity: Refer to letters in words. Model writing each letter (M, I, O) separately on a magnetic sketch board using directional language (e.g., M for MILO goes up, down, up, down) say letter name and sound for each letter, make the letter shapes in the air. The children will practice writing these letter shapes themselves in their own blank paged writing books with the instructor scaffolding their shaping using directional language. 


\section{Appendix B}

\section{Fidelity Coding Criteria}

\begin{tabular}{|c|c|c|c|c|}
\hline Fidelity Coding Criteria & Never & $\begin{array}{l}\text { Some } \\
\text { times }\end{array}$ & Mostly & Always \\
\hline \multicolumn{5}{|l|}{ Quality of Instruction } \\
\hline 1. Instructor uses clear and concise age appropriate language & 1 & 2 & 3 & 4 \\
\hline 2. Instructor provides clear expectations of children & 1 & 2 & 3 & 4 \\
\hline 3. Instructor provides clear instructions & 1 & 2 & 3 & 4 \\
\hline 4. Instructor ensures children understand instructions & 1 & 2 & 3 & 4 \\
\hline 5. Instructor clearly demonstrates and provides guidance for activities & 1 & 2 & 3 & 4 \\
\hline 6. Instructor maintains children's attention, engagement and interest & 1 & 2 & 3 & 4 \\
\hline 7. Instructor provides praise and encouragement & 1 & 2 & 3 & 4 \\
\hline 8. Instructor interacts positively with children & 1 & 2 & 3 & 4 \\
\hline 9. Instructor displays a positive and enthusiastic approach & 1 & 2 & 3 & 4 \\
\hline 10. Instructor displays a warm and approachable manner & 1 & 2 & 3 & 4 \\
\hline \multicolumn{5}{|l|}{ Instructor's adherence to program } \\
\hline $\begin{array}{l}\text { 1. Instructor's language is in general accordance with the program } \\
\text { script }\end{array}$ & 1 & 2 & 3 & 4 \\
\hline 2. All materials and resources are available and easily accessible & 1 & 2 & 3 & 4 \\
\hline $\begin{array}{l}\text { 3. All materials and resources used are in accordance with the program } \\
\text { activities }\end{array}$ & 1 & 2 & 3 & 4 \\
\hline 4. All components of the program session are completed & 1 & 2 & 3 & 4 \\
\hline
\end{tabular}

